\title{
Integrated gas field development: The Anjum story
}

\author{
F. J. Hollman' \\ NAM Schoonebeek; LAN/5; mail: P.O. box 28000, 9400 HH Assen \\ Manuscript received: 1 Aug 1999; accepted in revised form: 19 May 2000
}

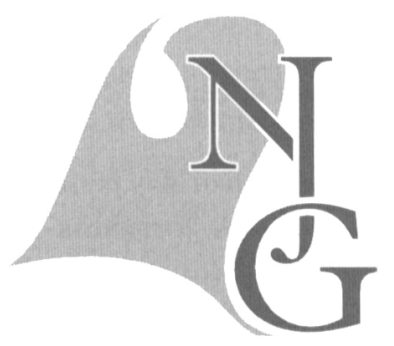

\begin{abstract}
In contrast to oil field development, gas field development requires tight integration of subsurface, surface and economic issues due to the difficulty of storing surplus produced gas and the large effect of the back-pressures in a surface network on the individual well performance. As a major gas supplier the Shell Group, and in particular NAM, has extensive experience in this field.

The gas production from onshore fields in the North Friesland area is a recent NAM development. A 10 million cubic meter per day LTS gas treatment installation located near the village of Anjum came on stream in 1997. Production initially started from 3 wells in 2 fields to deliver gas to the Gasunie grid at Grijpskerk. The total area comprises 10 fields and 4 remaining prospects and is planned to be fully developed by the year 2001, using wet gas pipelines to route the production to either the Anjum LTS installation or the Grijpskerk SilicaGel installation.

The Rotliegend reservoirs in this part of the Netherlands are very heterogeneous and require a more detailed subsurface simulation than feasible with the standard NAM tool for gas field development (GENREM). In addition, the area is close to the Waddenzee and based on extensive ecological research, NAM uses a stringent, self-imposed ecological constraint, whilst evaluating the development plans for this area. Detailed subsidence studies have been run using subsidence-modeling tools, which run under a software user-interface called FrontEnd, an in-house development by the Shell Group. Also running under this interface is an application for gas field development called Gas Field Planning Tool (GFPT). GFPT combines a detailed subsurface simulator with a surface simulator using a development planning module, which handles economic and operational aspects of the integrated model. Lastly, the interface gives access to a powerful command language and a mathematical toolbox, which can be used to define almost any missing functionality.

Making use of the flexibility offered by the FrontEnd interface and with help from available expertise in RTS (Shell Rijswijk), an integrated GFPT model was built, which not only incorporates operational and economic constraints, but also does optimization and subsidence analysis. The model is used to evaluate all development options and scenarios for this area in a consistent manner. Therefore, all proposed development plans are optimized within all applied constraints whether they are related to surface, subsurface, economic, or environmental aspects.

Production history and well performance are very close to those predicted by these detailed models, which will allow accurate prediction of future field performance and subsidence.
\end{abstract}

Keywords: Gas Field Planning, Friesland, Anjum, gas field software, prediction

\section{Exploration (1990 - 1995)}

In the early nineties, exploration by the NAM started to concentrate on an as yet, relatively green field area in the Netherlands: North East Friesland (Fig. 1). Two large $\left(20 \times 10^{9} \mathrm{~m}^{3}\right)$ initial discoveries in 1992
(ANJ-1 and MKZ-1) suggested, that more gas might be present in the area. The ANJ-1 well also found the reservoir overpressurized, similarly to the Ameland field (located some $15 \mathrm{~km}$ north of Anjum), indicating, that both reservoirs probably belonged to the same overpressure cell. 


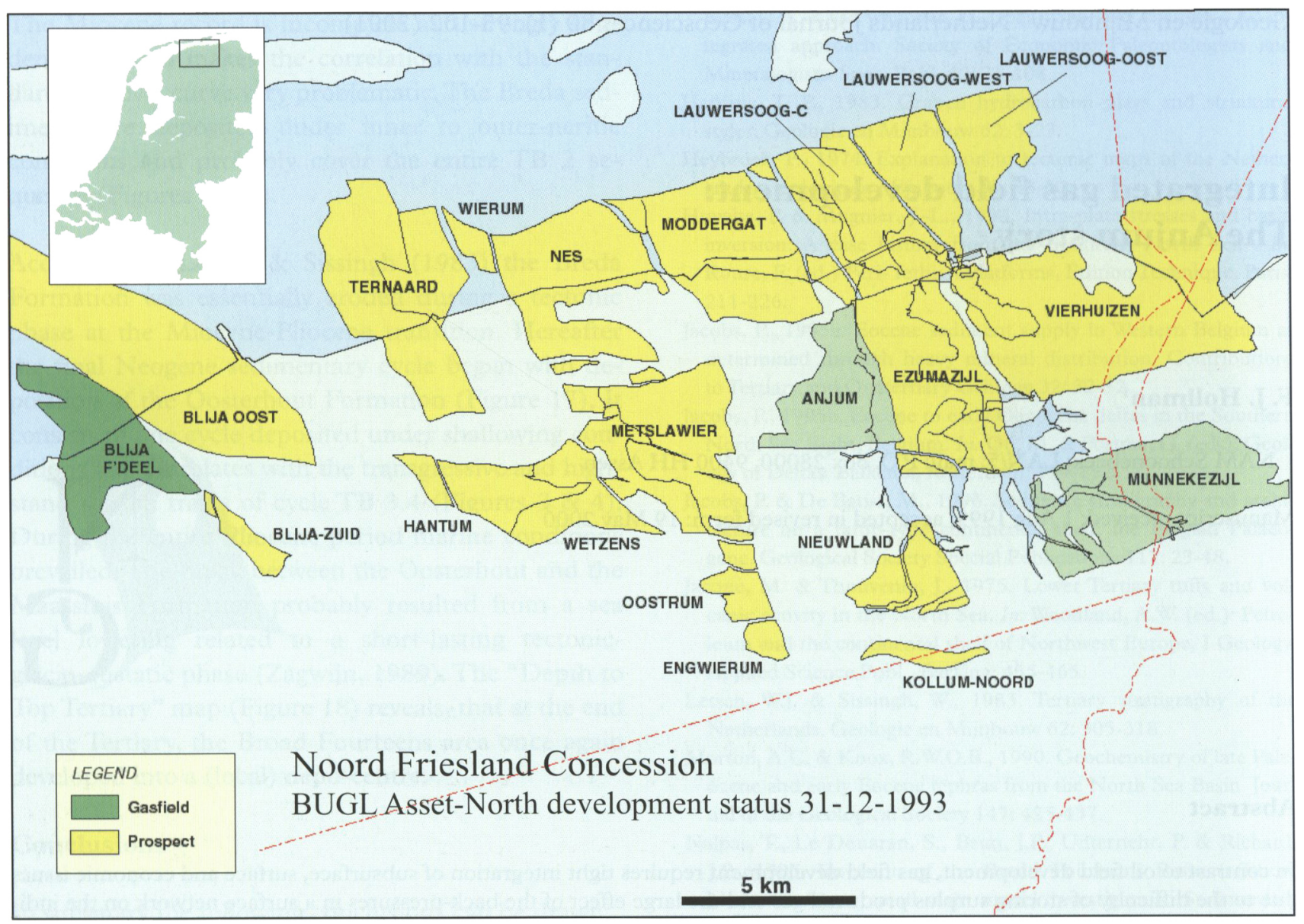

Fig. 1. Location map from 1993 of the prospects and gas fields in the North Friesland concession (BUGL = Business Unit Gas Land).

As Munnekezijl and Anjum are situated on different sides of the Lauwersmeer, two separate developments were pursued. In the case of Anjum, as distance to the nearest processing facilities was in the order of some $20 \mathrm{~km}$, a new processing facility was envisaged. Given the flat, open character of the environment (Fig. 2), minimal and localized intrusion in the landscape was required by the local authorities. This led to a design of centralized processing facilities with minimal facilities being present on satellite locations. Figure 3 shows the status of the development by end 1995 . Central processing facilities at Anjum are indicated in blue and satellite locations at various places, where exploration results were positive, are shown in red.

Concerns were raised with respect to subsidence of the area, which was partially overlain by the Netherlands largest nature reserve, the Waddenzee. Figure 4 shows the Peazemerlannen, with four distinct main vegetation zones. The difference in surface elevation between the left and the south of the picture is just some $30 \mathrm{~cm}$ over a distance of some 500 meters. Clearly subsidence of this area could have a significant influence on the existing environment. Thus, an environmental study was initiated immediately (Van Duin, Dijkema \& Zeegers, 1998) in order to quantify the effect of possible gas production on the Waddenzee.

The volumes of the gas resources in the area were estimated at some $80 \times 10^{9} \mathrm{~m}^{3}$ of gas, with a high case scenario up to $130 \times 10^{9} \mathrm{~m}^{3}$. With the commercial terms, applicable at that time, it meant that some $30 \times$ $10^{6} \mathrm{~m}^{3} /$ day processing capacity would be required to optimize the new gas sales contract, which was still to be negotiated. However, exploration and appraisal drilling to firm up these volumes would take some time. Therefore, a flexible development plan was opted for with the gas treatment plan comprising several processing trains, and only the first train being built initially. As more reserves were being found, additional process capacity could be installed.

During 1994 well ANJ-2 was drilled from the Anjum location and discovered the Metslawier accumulation to the west of Anjum. The Oostrum discovery (well EWM-1) extended the overpressurised region towards the south. Two further exploration wells 


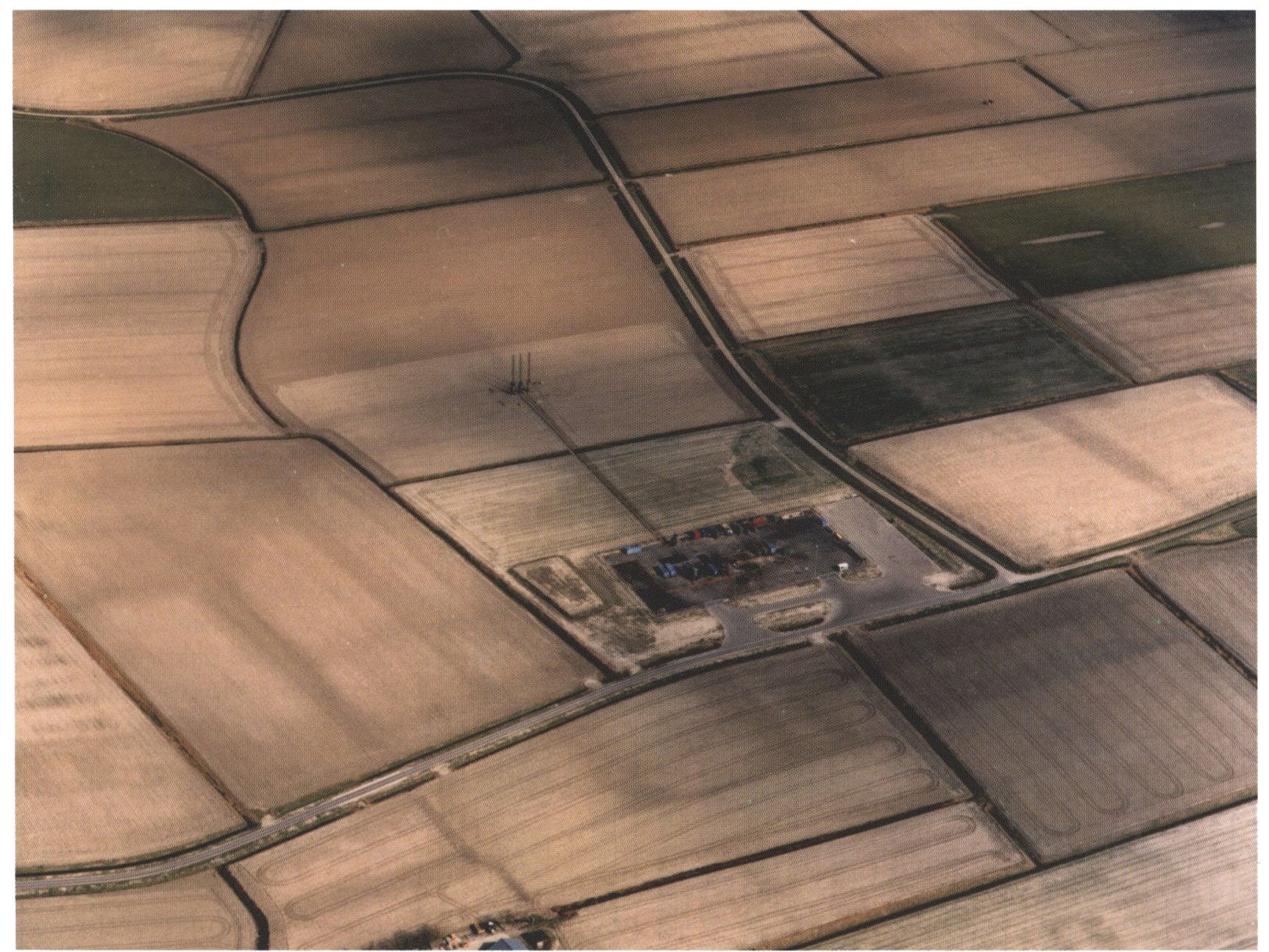

Fig. 2. Aerial photograph of the Anjum facilities in the typical Frisian landscape.

(MGT-1 and MGT-2) in 1995 proved gas in the fault blocks right north of Anjum (Moddergat) and Metslawier (Nes). By that stage the area had proven enough gas to warrant building the first train and start commercial production.

However, large uncertainties still existed in the subsur-

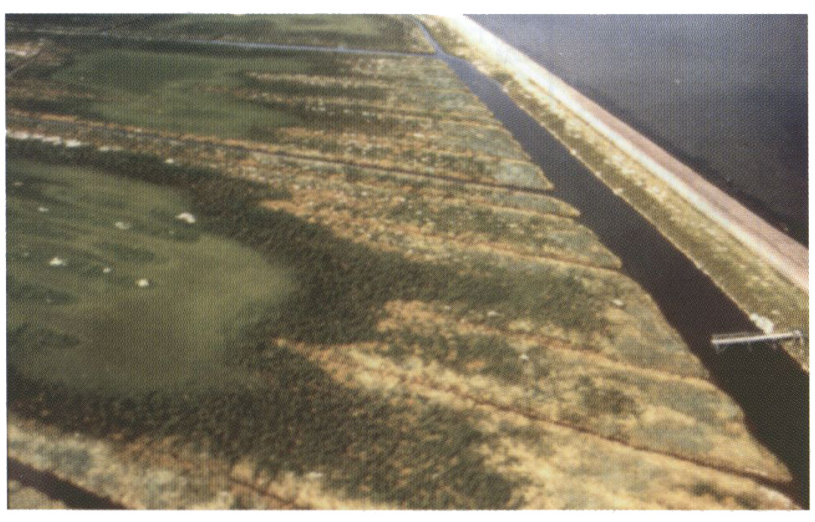

Fig. 3. Aerial photograph of the Peazemerlannen, a nature reserve along the Waddenzee dike. Clearly visible are the 4 main vegetation zones, differing $30 \mathrm{~cm}$ in elevation. face data. The Anjum free water level (FWL) still had considerable uncertainty due to scatter in the RFT pressures (Fig. 5) and the fact, that a shale layer is present near the likely FWL, making an accurate interpretation impossible. Moreover, productivity of the lower units was not proven which gave quite some uncertainty as to the number of wells required to produce $\times 10 \times$ $10^{6} \mathrm{~m}^{3} /$ day, the design capacity of the first plant.

One legacy remains from earlier times, when less integration took place. The naming convention for the wells at NAM is a combination of location name and slot number. With multiple fields drilled from a single location these days, the well naming convention is becoming more and more of an issue. The following is illustrative of this problem and the confusion it may potentially cause. We quote the wells in chronological order of drilling:

ANJ-1 was the first well to penetrate the Anjum reservoir (1992),

ANJ-2 was the first well to penetrate the Metslawier reservoir (1994), 
ANJ-4 is the second well to penetrate the Anjum structure (1997),

ANJ-3 is the first well to penetrate the Ezumazijl structure (1998),

Similarly,

MGT-1 is the discovery well of Moddergat,

MGT-2 is the discovery well of Nes.

\section{Appraisal (1995 - 1997)}

In order to reduce the petroleum engineering uncer- tainties with respect to productivity, an extensive well-test campaign was performed on ANJ-1. With a FBU and PLT (see glossary of abbreviations) measuring the performance improvement with every additional perforation, the productivity of unit 6 in ANJ-1 was confirmed; Anj-1 produced some $0.5 \times$ $10^{6} \mathrm{~m}^{3} /$ day of dry gas from unit 6 . Although all units produced gas, some clear differences in productivity of the various units were observed. Total well productivity with 5 " tubing rose from a predicted $2.9 \times 10^{6}$ $\mathrm{m}^{3} /$ day at 100 Bar drawdown (Q100) to some $5.5 \times$

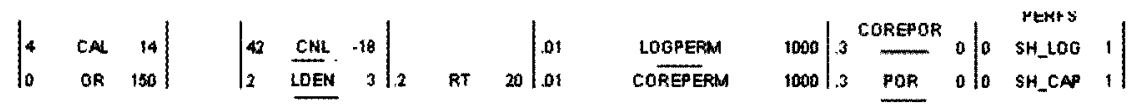

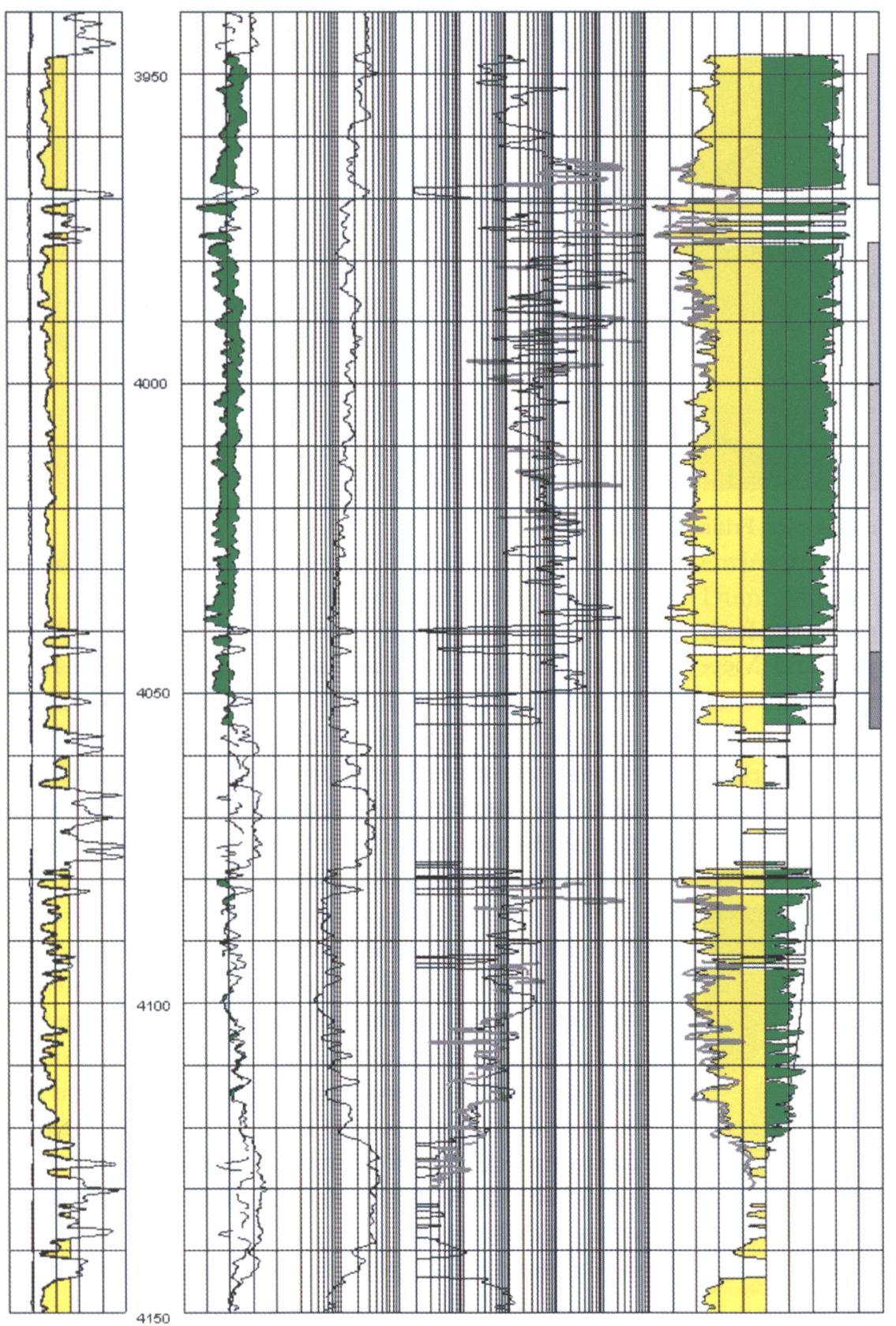

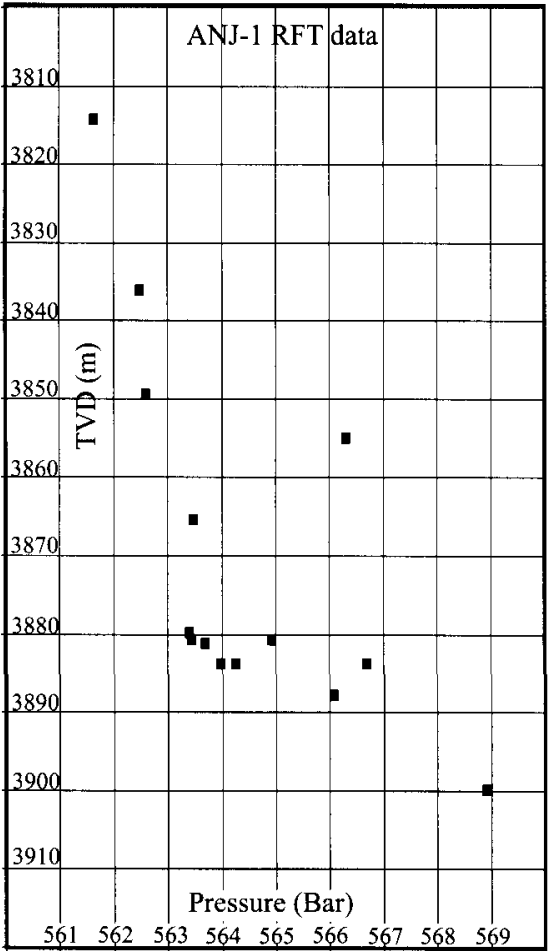

Fig. 5. RFT data at true vertical depth. The $3800 \mathrm{~m}$ RFT depth correlates to $4000 \mathrm{~m}$ in figure 4 and the $3900 \mathrm{~m}$ RFT depth correlates to $4100 \mathrm{~m}$ in figure 4 .

Fig. 4. Wireline logs and interpretations indicating reservoir quality and position of the Anjum gas reservoir. Depth values are along-hole valeus. 
$10^{6} \mathrm{~m}^{3} /$ day provided a 7 " tubing was installed. This indicated that although it might be feasible to fill the plant initially with just ANJ-1 and ANJ-2, a third well would be required to guarantee longer term plateau production. An appraisal well down dip in Anjum, to resolve the FWL uncertainty, combined with an (semi-) horizontal sidetrack updip was designed and drilled in 1997 and proved up additional reserves. In this way, development of the Moddergat/Nes satellite could be postponed by 2 years, improving project economics and also considerably levelling out activity levels.

With 4 adjacent fault-blocks all being gas bearing, it was vital to plan the development in a fully integrated manner. Rather than evaluating individual fields, a top structure map for the whole area was generated, which fitted all well data. For volumetric estimates, porosity and other reservoir properties were mapped rather than using averaged well volumes per fault block. This captured a trend of decreasing reservoir quality towards the north.

The RFT measurements were also re-evaluated. With similar pressures and temperatures, the gas and water gradients in each of the four blocks should be the same, and also be consistent with pressure gradient surveys performed after the well tests. Applying this restriction narrowed the range of fluid gradients considerably, and this in turn reduced the uncertainty in the FWL of each block. These revised contacts were in line with possible spill points observed on the new structure map, improving the confidence in the new interpretation. The RFT results from the appraisal leg from Anj-4 confirmed and refined the new interpretation.

A surprisingly large number of fluid samples taken below the FWL were reported to contain gas. In combination with a mismatch between the $\log$ derived and the capillary-pressure-curve derived saturations, this indicated the area could be in an imbibition phase, rather than a drainage phase. In case the capillary pressure curves would predict the correct saturations, the dry gas production observed below the inferred FWL in well ANJ-1 from unit 6 would occur at a rather low gas saturation of $30 \%$. From the logs a gas saturation of some $40 \%$ is interpreted for this zone, which from a productivity point of view made more sense. Therefore, the base model became imbibition, and $\log$ saturations were used to determine GIIP.

Using all available core data, and matching this with the production test results from the existing wells, subsurface models were built which incorporated the structural heterogeneity of the fields by means of 16 layers. Two of these sixteen layers could be made to model the High Porosity, High Permeability Streaks (HPS) observed in cores. The typical reservoir quality of these streaks was some 8 to $10 \%$ higher in porosity compared to the surrounding rocks, giving a total porosity of the streaks of some $25-30 \%$. Permeability increased correspondingly to values of 1 Darcy or higher. Using this reservoir model, a semi-horizontal Anjum development well was designed, with a predicted initial capacity of $7 \times 10^{6} \mathrm{~m}^{3} /$ day at $100 \mathrm{bar}$ drawdown.

Initially only 3 wells would be hooked up to the gas processing facilities. To cater for future production demands the tubing size of wells ANJ-1 and ANJ-2 was increased to $7 "$. With the thick, horizontal well capable of producing $27 \times 10^{6} \mathrm{~m}^{3} /$ day installing 7 " tubing in wells ANJ-1 and ANJ-2 was not needed to meet the $10 \times 10^{6} \mathrm{~m}^{3} /$ day contracted volume. However, increased productivity of these two wells would provide sufficient spare capacity to meet the contracted volume, should any of the three wells fail for any reason.

Given that the area was being developed under a "pool arrangement", warranted even closer integration of commercial and surface aspects. In a pool arrangement a group of fields is commercially treated as a single field. If a new field is discovered, its reserves are added to the pool's reserves allowing an increase of the pool's annual contract quantities (acq) without the new field having to be developed immediately. This improves the economics of especially smaller fields by allowing phased or sequential developments.

The key factor of the pooling concept is, that additional, newly discovered gas reserves underpin an increase in the ACQ for the pool. Actual development of the newly discovered field may, however, be deferred. Economically this could be very attractive as it postpones major investments whilst accelerating revenues. Therefore, the area must be looked at in its entirety, rather than as a set of independent fields. In order to model these effects correctly, every issue was included in an integrated development model which incorporated surface, subsurface and contractual models. Also exploration efforts had to continue to prove up additional reserves, and an exploration expectation result was imported into the simulator to predict meaningful annual allowable production volumes. As a consequence this required a close liaison with the exploration and production departments. As the total area was just south of, and partially right 


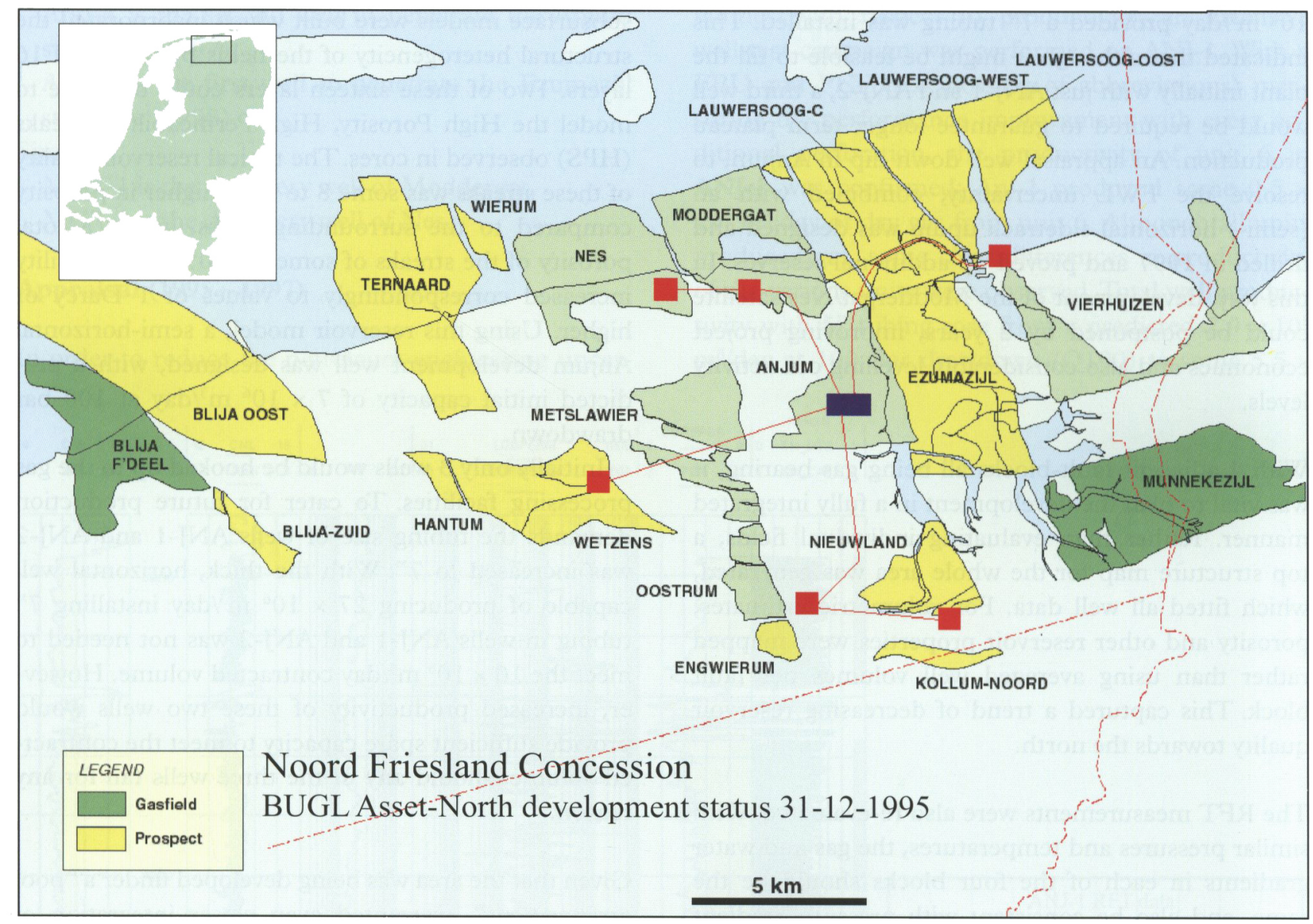

Fig. 6. Development status map of the North Friesland concession by end 1995. Gas pipelines and facilities are shown in red.

beneath the environmentally sensitive Waddenzee, surface subsidence was another issue to consider. As indicated by the photograph of the Peazemerlannen area (Fig. 4), not just the depth of the subsidence bowl, but the rate at which it would form, and its impact on the changing water table and vegetation, was the most important environmental effect to consider. This concern was identified very early-on, and extensive external research on sand suppletion and erosional effects in those parts of the Waddenzee, likely to be affected, had taken place following the discovery of the Anjum reservoir.

That study concluded, that on a very local scale (e.g. a single sandbar or a channel) natural variations in water depth and sediment surface elevation are in the order of approximately 80 centimeters at a time scale of month to years. However, on a larger scale (e.g. the Peazamerlannen saltmarsh as a whole) vertical variations in average high tide level or in sediment surface elevation due to changes in sand suppletion are only on the order of a centimeter per year. Thus, if subsidence is less than $1 \mathrm{~cm} / \mathrm{year}$, its effects are expected within the range of natural fluctuations of the sedimentary system. Hence environmental impacts are expected to be minimal.
In order to ensure strict adherence to this self-imposed environmental constraint, whilst evaluating the various development scenario's, a dynamic link between the integrated field and the subsidence model was built. Effectively, this means that, rather than calculating the environmental impact at the end of a simulation, prognosed subsidence calculations were done during simulated field developments. This automated interpretation was used to adjust the development scenario if required, to ensure that the development would be sustainable.

\section{Development (1997-2040??)}

With the emphasis shifting towards development of the region's gas reservoirs, exploration efforts were looked at from a different point of view. Examples of this are:

- Completion of well LWO-1 was delayed until a chrome tubing string became available, eliminating the need to work the well over and improving the field life cycle costs.

- More focus on the development requirements of exploration. Thus a high risk well from a producing location (Ezumazijl), became more attractive than 
a large volume well (Wierum, Ternaard) in a remote, as yet undeveloped area.

- Rather than drilling the best well to delineate the field, wells are now planned such, that they can be used to optimally produce the volumes discovered. In well LWO-3, the target was actually adjusted updip to ensure that if a shallow FWL was found, the well could be produced without prior sidetracking. This actually meant that in case of a deep FWL, only a gas-down-to would be established, and a second well would be required to delineate the field to its full extent. However, under those circumstances the volumes in place would justify drilling a second well.

The Anjum plant was brought on stream in Q3 in 1997 allowing the horizontal development well to be brought in production. Its measured Q100 of $7.3 \times$ $10^{6} \mathrm{~m}^{3} /$ day gave confidence in the model which, with some production history included, predicted a Q100 of $6.8 \times 10^{6} \mathrm{~m}^{3} /$ day. With the work-overs on the other wells being partly successful, the high capacity horizontal well was actually required at all times to provide the required production capacity. Hence, unconventional techniques monitoring performance of this successful well had to be developed.

A full set of operational data (tubing head temperature (THT) and pressure (THP), flow-rate, sand rate) was collected via the operational control monitors at a time scale of minutes. Two years later and after $15 \%$ of the reserves have been produced, these data still form the only basis for determining the productivity of the horizontal well.

Besides detailed data for well performance analysis, daily production data formed an ideal data set to test the validity of the simulation models, especially for the wells which are produced at a stable rate (no pressure fluctuations).

During the summer of 1998 , wellhead problems on ANJ-1 gave an unique opportunity to obtain bottom hole $(\mathrm{BH})$ data to ascertain the accuracy of the THP match. With close co-operation from the Operations department, a gauge was left hanging for two months in ANJ-1, to gather valuable bottom-hole reservoir pressure data, and observe the interference between ANJ-1 and ANJ-4, which gives a good indication of large scale reservoir permeability.

Figure 7 shows the THP match for ANJ-1, one of the wells that was kept on a stable base load rate. It shows a rather accurate match at a low flow rate, but the match deteriorates at late times when the flow-rate is higher. Given, that the $1998 \mathrm{BH}$ survey was matched accurately, a BH pressure survey during the 1999 plant shutdown will be needed to calibrate the model further. If the THP match had continued in 1999, no

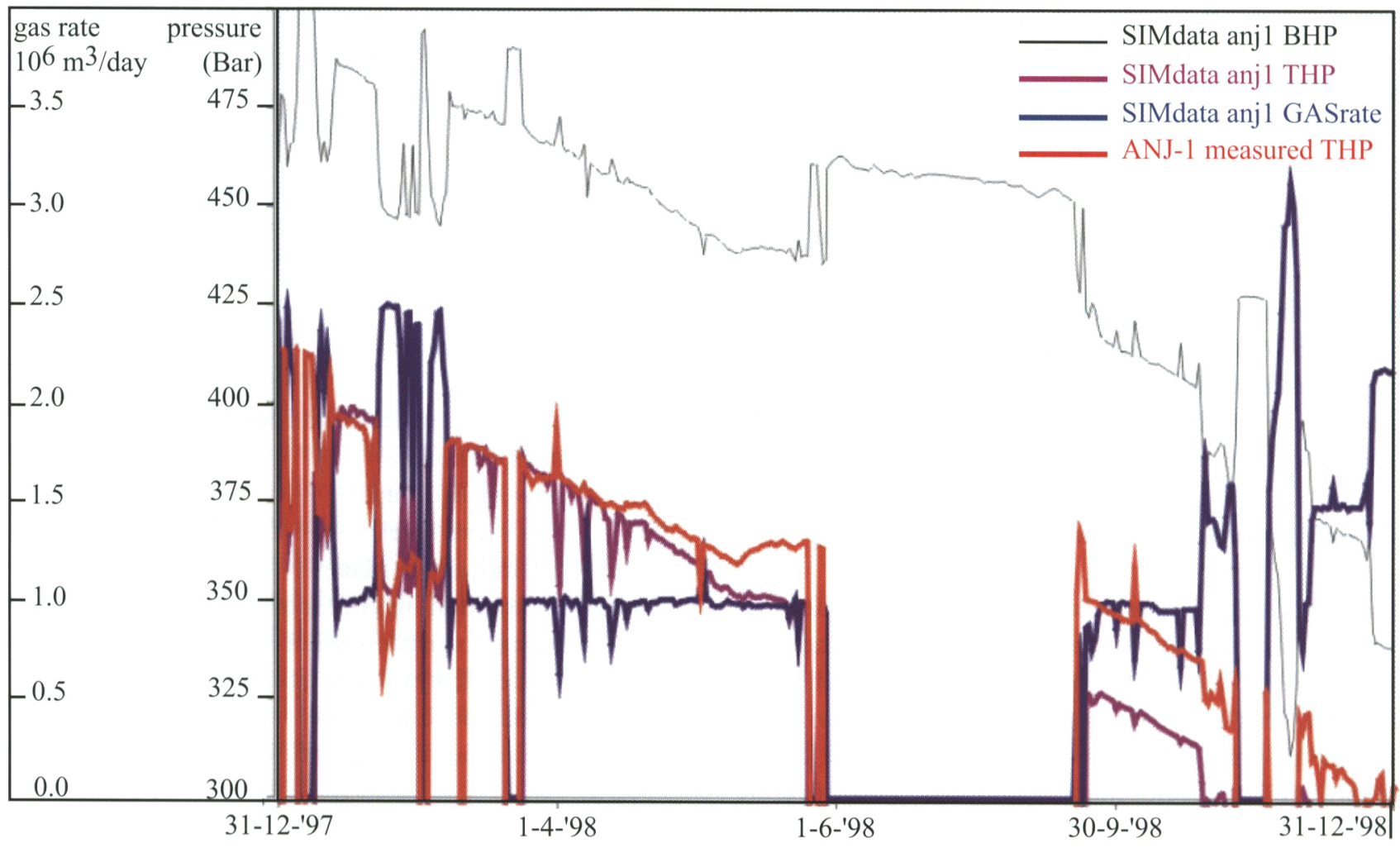

Fig. 7. History match of the Anjum field. 
SPG survey would be required, saving money and minimizing operations.

Similarly, operational measurements, complemented with special down-hole Production Logging Tool (PLT) data, have been used to gather data to find the source of a salt contamination of the gas, which caused operational problems.

\section{Controlling changes}

With the final gas sales contract in place, the actual maximum required contract capacity to guarantee the sales volume was actually lower than expected, reducing the required processing capacity from $25 \times 10^{6}$ $\mathrm{m}^{3} /$ day to $21 \times 10^{6} \mathrm{~m}^{3} /$ day. This meant, that the scope of the development went down from 3 to 2 process trains.

Heavier gases discovered in the southern fields, combined with dew-point problems observed in the first process train, indicated, that exporting the gases from the southern fields to a different (silica gel) installation at Grijpskerk might be an economically attractive alternative development option as a duplicate second train was no longer technically viable.

Recent delays in obtaining the relevant environmental permits to produce the Moddergat and Nes accumulations have caused a drop of available well production capacity. It also causes significant delays in the expected drilling and hookup date of parts of the pool. The consequence: a reduction in the annual contract sales and capacity requirements to such an extent, that the current development consists of just one process train in Anjum, and rerouting the gas from the southern fields to the Grijpskerk plant.

The automated coupling of the subsurface models with the subsidence model has allowed NAM to assess within a few days the implications of these changes in the development plan on the environment and on the production strategies.

\section{Conclusions and results}

By integrating all data sets for various subsurface disciplines, a considerably improved model of the subsurface has been built. This can be concluded from the fact, that the model, after 2 years and some $3 \times$ $10^{9} \mathrm{~m}^{3}$ gas production, is very much the same model on which the development was based. This accurate subsurface definition at an early stage of the project has helped making the right project decisions and gave an early warning of potential problems (e.g. water production).

Integrating the various commercial opportunities with the environmental issues, a integrated development plan has been devised which has no significant environmental impact on the Netherlands' most important nature reserve. Moreover, by applying this life-cycle approach from the day the well was drilled, helped optimizing operations and completions, thus saving work-over costs and risks.

Combining commercial and environmental aspects with the reservoir models in one large integrated model created a huge model with long running times (up to 36 hours for a pool life- cycle forecast). However, as detailed evaluation of unattractive scenarios was avoided, total simulation turnaround time for a study was significantly reduced and the long model running times did not create a bottleneck.

Continuous communication between operations and petroleum engineering ensured, that (sub)surface data gathering now takes place as an integral part of the daily production process, minimizing the costs and associated production deferral rates caused by separate data gathering exercises. Provided wells are producing at reasonably stable rates and an accurate translation of TH pressures to downhole conditions is available, this method may be used anywhere.

\section{References}

Van Duin, Dijkema \& Zegers, 1998. Veranderingen in Bodemhoogte in de Peazemerelannen. Instituut voor Bos en Natuur onderzoek, IBN-rapport 326, ISSN 0928-6888

\section{List of Abbreviations:}

ACQ annual contract quantities

$\mathrm{BH}$ bottom hole

FBU flowing built up

FWL free water level

GIIP gas initially in place

PLT production logging tool

RFT repeat formation tester

SPG suspended pressure gauge

THP tubing head pressure

THT tubing head temperature 